\title{
Antioxidant Activity and Total Phenolic Content of Different Skin Coloured Brinjal (Solanum melongena)
}

\author{
K.M. Somawathi, V. Rizliya ${ }^{1}$, D.G.N.G. Wijesinghe ${ }^{1}$ and W.M.T. Madhujith ${ }^{1}$ \\ Postgraduate Institute of Agriculture \\ University of Peradeniya \\ Sri Lanka
}

\begin{abstract}
The aim of this study was to determine the antioxidant activity and the total phenolic content (TPC) of Solanum melongena of different skin colours/patterns: purple with no lines (S1), light purple with lines (S2), dark purple with lines (S3), pink coloured (S4) and purple with green lines (S5). The antioxidant activity was evaluated using different analytical techniques: DPPH and ABTS free radical scavenging assays, ferric reducing antioxidant power (FRAP) assay and ferric thiocyanate (FTC) test. The results showed that there was a significant difference $(P<0.0001)$ between the skin colour/pattern and antioxidant activity. Total phenolic content (TPC) and FRAP values of brinjal extracts varied from $48.67 \pm 0.27$ to $61.11 \pm 0.26 \mathrm{mg} \mathrm{GAE} / 100 \mathrm{~g}$ fresh weight and $4.19 \pm 0.11$ to $7.46 \pm 0.26 \mathrm{mmol}$ of $\mathrm{FeSO} 4 \mathrm{~g}$ fresh weight, respectively. Brinjal with dark purple lines (S3) showed the highest antioxidant activity as quantified by FRAP and TPC while brinjal with light purple lines (S2) showed the least. Purple brinjal with no lines (S1) displayed the highest DPPH radical scavenging activity with an $I C_{50}$ value of $3.51 \pm 0.62 \mathrm{mg} / \mathrm{ml}$ while $S 3$ demonstrated the strongest total antioxidant activity as measured by ABTS assay with an inhibition of $40.45 \%$. In the FTC assay, the percent inhibition of linoleic acid oxidation ranged from $15.11 \pm 1.31$ to $26.74 \pm 2.85$.
\end{abstract}

Keywords: Antioxidant activity, lipid peroxidation, phenolic content, skin colour, $\underline{\text { Solanum }}$ melongena

\section{INTRODUCTION}

Brinjal (Solanum melongena L., Solanaceae), one of the most widespread vegetable consumed around the world contains a variety of phytochemicals such as flavonoids which provide a myriad of health benefits. Brinjal fruit is reported to be a rich source of ascorbic acid and phenolics, both of which are powerful antioxidants (Vinson et al., 1998). Brinjal extracts have been reported to successfully suppress the development and growth of tumours, lung cancer (Matsubara et al., 2005), inhibit inflammation (Keli et al., 1996), and cardiovascular diseases (Knekt et al., 1996 and 1997). Brinjal has received an increased interest among consumers and researchers worldwide because of its health benefits and is ranked amongst the top 10 vegetables in terms of antioxidant capacity (Cao et al., 1996).

Hydroxycinnamic acid conjugates are the main class of phenolics present in brinjal. Of these, chlorogenic acid (5-O-caffeoylquinic acid and its isomers) typically accounts for 70-95\% of total phenolics in brinjal flesh (Whitaker and Stommel, 2003). The beneficial effects of

\footnotetext{
1 Department of Food Science and Technology, University of Peradeniya, Peradeniya, Sri Lanka

* Corresponding author:
} 
chlorogenic acid and related compounds present in minor quantities in brinjal are numerous. Furthermore, they are reported to impart anti-tumoral activities (Sawa et al., 1998; Triantis et al., 2005).

Brinjal is one of the commonest vegetables consumed in Sri Lanka. The unripe fruit is primarily used as a cooking vegetable for various dishes. Different varieties of brinjals of different size, shape and colour are available in the market. The most widely grown variety in Sri Lanka is the elongated ovoid or slender ones with a dark purple skin. Extract of brinjal with purple skin has been shown to possess a high capacity in the scavenging of superoxide radicals and inhibition of hydroxyl radical generation by chelating ferrous iron (Kaneyuki et al., 1999; Noda et al., 2000). Despite the beneficial effects associated with brinjal, only a limited literature is available on the antioxidant efficacy, especially with respect to colour difference. Considering this fact and the importance of brinjal in cuisines, the present study was carried out to evaluate and compare the in vitro antioxidant activity of brinjal with respect to skin colour.

\section{MATERIALS AND METHODS}

\section{Chemicals and reagents}

All the chemicals and solvents used were of analytical grade. Folin Ciocalteau's reagent, gallic acid, 2,2-diphenyl-1-picrylhydrazyl hydrate (DPPH), 2, 2'-azobis (2ethylbenzothiazoline-6-sulfonic acid) diammonium salt (ABTS), 2,2'-azobis (2methylpropanimidamide) dihydrochloride (AAPH), 2, 4, 6-tris (2-pyridyl)-1, 3, 5-triazine (TPTZ), linoleic acid, thiobarbaturic acid were purchased from Sigma Aldrich Chemical Company, USA while other chemicals used were purchased from HIMEDIA Chemicals Ltd. UK.

Fresh matured brinjals with different skin colour viz., purple with no lines (S1), light purple with lines (S2), dark purple with lines (S3), pink coloured (S4) and purple with green lines (S5) were purchased fresh from Pambahinna, Belihuloya (Figure 1).

\section{Preparation of water extracts}

Approximately $50 \mathrm{~g}$ of fresh and disease free brinjal pods were washed with pure water and sliced. The slices were well blended in a laboratory blender and filtered through a cotton mesh. The resulting extracts were stored at $-20{ }^{\circ} \mathrm{C}$ until further analysis. The extracts were appropriately diluted with distilled water and used for chemical analysis.

\section{Determination of total phenolic content (TPC)}

The total phenolic content (TPC) of the extracts was determined colourimetrically as described by Kriengsak et al. (2006) with some modifications. The results were expressed as $\mathrm{mg}$ gallic acid equivalents (GAE) per $100 \mathrm{~g}$ of fresh weight.

\section{Determination of DPPH radical scavenging activity}

The DPPH assay was performed according to the method described by Brand-Williams et al. (1995) with modifications. DPPH solution $(2 \mathrm{ml})$ was added to different volumes $(150,300$, $450,600,750,900 \mu \mathrm{l})$ of aqueous brinjal extract and diluted with distilled water until the 
volume reached $4 \mathrm{ml}$ and allowed to stand for $30 \mathrm{~min}$ in dark at ambient temperature. The absorbance was read at $517 \mathrm{~nm}$. Ascorbic acid was used as the reference antioxidant and the antioxidant capacity was expressed as $\mathrm{IC}_{50}$ value.

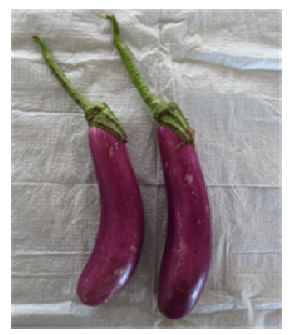

S1-purple with no lines

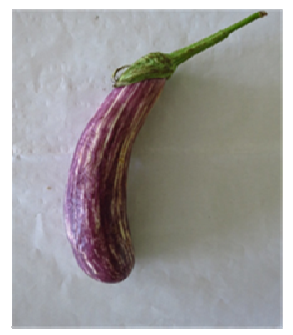

S2-lught purphle with lines

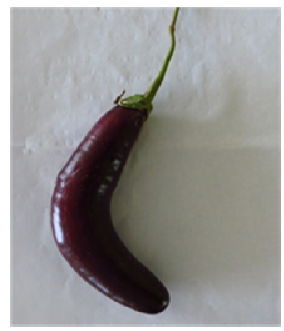

S3-dark purple with lines

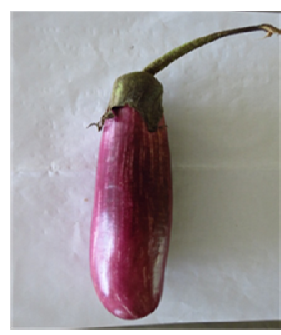

54-punk coloured

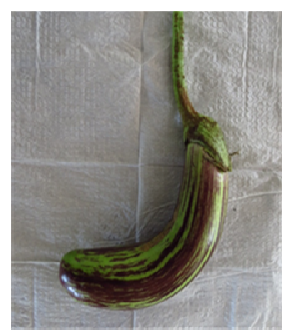

S5-purple with greent lines

Fig. 1. Different skin colours of brinjal used for the study

\section{Determination of ABTS radical scavenging activity}

The total antioxidant capacity of the extracts was determined using ABTS radical scavenging assay. The $\mathrm{ABTS}^{+}$was generated by reacting ABTS with AAPH, which acts as the radical generator. Each extract $(150 \mu 1,25 \mathrm{mg} / \mathrm{ml})$ was mixed with $2.85 \mathrm{ml}$ of ABTS radical solution and absorbance was read over 6 minutes at $1 \mathrm{~min}$ interval at $734 \mathrm{~nm}$. The radical scavenging activity after lapse of $6 \mathrm{~min}$ was calculated as percentage of $\mathrm{ABTS}^{\circ+}$ discolouration (Robereta et al., 1999).

\section{Determination of antioxidant activity using FRAP assay}

Ferric reducing antioxidant power (FRAP) assay was performed according to the method explained by Kriengask et al. (2006) with modifications. The FRAP reagent included $10 \mathrm{mM}$ TPTZ, $20 \mathrm{mM} \mathrm{FeCl}_{3}$, and $0.3 \mathrm{M}$ acetate buffer at 1:1:10 (v/v) ratio. FRAP reagent $(3 \mathrm{~mL})$ at $37{ }^{\circ} \mathrm{C}$ was mixed with $150 \mu \mathrm{l}$ of the extract. After a lapse of $4 \mathrm{~min}$, the absorbance was read at $593 \mathrm{~nm}$ against a reagent blank and the results were expressed as mmol of $\mathrm{Fe}^{2+} / \mathrm{g}$ fresh weight using a $\mathrm{Fe}^{2+}(0.05-0.50 \mathrm{mmol})$ standard curve.

\section{Ferric Thiocyanate (FTC) test}

Brinjal extracts were mixed with $4.1 \mathrm{ml}$ of linoleic acid $(2.5 \%$ in ethanol $99.5 \%), 8 \mathrm{ml}$ of phosphate buffer $(0.02 \mathrm{M}, \mathrm{pH} 7)$ and $3.9 \mathrm{ml}$ distilled water. The mixture was placed in a dark oven maintained at $40-45^{\circ} \mathrm{C}$. Following incubation, $0.1 \mathrm{ml}$ of the solution was drawn and $9.7 \mathrm{ml}$ of $75 \%$ ethanol and $0.1 \mathrm{ml}$ of $30 \% \mathrm{NH}_{4} \mathrm{SCN}$ were added. Precisely 3 min after the 
addition of $0.1 \mathrm{ml}$ of $0.002 \mathrm{M}$ ferrous chloride in $3.5 \% \mathrm{HCl}$ to the reaction mixture, the absorbance was read at $500 \mathrm{~nm}$ and the inhibition of lipid oxidation was measured (HudaFaujan et al., 2007).

\section{Statistical analysis}

Each antioxidant activity assay was performed four times using the same extract in order to determine their reproducibility and results were expressed as mean \pm SD. Statistical analysis was performed using the SAS 9.1.3 version.

\section{RESULTS AND DISCUSSION}

\section{Total Phenolic Content (TPC)}

Total Phenolic Content (TPC) reported as the gallic acid equivalent is presented in Table 1. $S$. melongena was found to have varying levels of TPC, ranging from $48.67 \pm 0.27$ to $61.11 \pm 0.26 \mathrm{mg} \mathrm{GAE} / 100 \mathrm{~g}$ on fresh weight basis. The TPC was markedly higher in S3 and S1 than the other three samples. S2 had the lowest total phenolic content which was significantly lower than all other extracts. Plant phenolics have received much attention as potential natural antioxidant in terms of their ability to act as both efficient radical scavengers and metal chelators. Therefore, it is worthwhile to determine the total amount of phenolic content in the plant chosen for the study.

Table 1. Total phenolic content and antioxidant activity of five different varieties of brinjal

\begin{tabular}{lccccc}
\hline Extract & $\begin{array}{c}\text { TPC } \\
(\mathrm{mg} / 100 \mathrm{~g})\end{array}$ & $\begin{array}{c}\text { DPPH }\left(\mathrm{IC}_{50}\right) \\
(\mathrm{mg} / \mathrm{ml})\end{array}$ & $\begin{array}{c}\text { ABTS } \\
(\% \text { inhibition })\end{array}$ & $\begin{array}{c}\text { FRAP } \\
(\mathrm{mmol} / \mathrm{g})\end{array}$ & $\begin{array}{c}\text { FTC } \\
(\% \text { inhibition })\end{array}$ \\
\hline S1 & $60.94 \pm 0.52$ & $3.51 \pm 0.62^{\mathrm{c}}$ & $27.33 \pm 0.57^{\mathrm{b}}$ & $6.77 \pm 0.03^{\mathrm{b}}$ & $26.74 \pm 2.85^{\mathrm{a}}$ \\
S2 & $48.67 \pm 0.26$ & $4.78 \pm 0.65^{\mathrm{a}}$ & $17.78 \pm 0.38^{\mathrm{c}}$ & $4.19 \pm 0.11^{\mathrm{d}}$ & $15.11 \pm 1.31^{\mathrm{d}}$ \\
S3 & $61.11 \pm 0.26$ & $3.78 \pm 0.90^{\mathrm{c}}$ & $40.45 \pm 1.17^{\mathrm{a}}$ & $7.46 \pm 0.26^{\mathrm{a}}$ & $25.36 \pm 1.01^{\mathrm{a}} \mathrm{b}$ \\
S4 & $56.00 \pm 0.53$ & $4.87 \pm 1.47^{\mathrm{a}}$ & $23.90 \pm 0.07^{\mathrm{b}}$ & $4.64 \pm 0.37^{\mathrm{c}}$ & $24.50 \pm 0.87^{\mathrm{b}}$ \\
S5 & $54.38 \pm 0.51$ & $3.96 \pm 1.28^{\mathrm{b}}$ & $24.02 \pm 0.24^{\mathrm{b}}$ & $4.81 \pm 0.35^{\mathrm{c}}$ & $20.65 \pm 0.57^{\mathrm{c}}$ \\
\hline
\end{tabular}

Data are presented as Mean SD of four estimations.

Means followed by the same letters in a column are not significant $(\mathrm{p}=0.0001)$.

Phenolic compounds such as N-caffeoylputrescine, 5-caffeoylquinic acid, and 3-acetyl-5caffeoylquinic acid were identified from brinjal pulp (Singh et al., 2009). Noda et al. (2000) also reported that nasunin, delphinidin-3-( $p$-coumaroylrutinoside)-5-glucoside, was a representative anthocyanin in eggplant peel. Generally, the peel contains higher amounts of phenolics, anthocyanins, and flavonols than pulp tissue (Tomás-Barberán et al., 2001; Jang et al., 2010). Compared to pulp, brinjal peel contains higher amounts of those compounds. Especially, the anthocyanin content in the peel is much higher than the pulp (Jung et al., 2011). Significantly higher TPC in $S 1$ and $S 3$ compared to $S 2$ on fresh weight basis may be mainly due to the high anthocyanin content of the brinjal peel (Brown, 2005). 
Nisha et al. (2009), in their work found the TPC of brinjal to be in the range of $49.02 \pm 1.3$ $106.98 \pm 2.2 \mathrm{mg}$ gallic acid equivalents $/ 100 \mathrm{~g}$ which correlates well with our findings. They studied the antioxidant activity of four different varieties of brinjal and the purple colour small size brinjal exhibited better antioxidant activity which was attributed to the higher phenolic and anthocyanin contents. In another study, where 69 S. melongena varieties were studied the TPC ranged between 280 to $834 \mathrm{mg} / \mathrm{kg}$ (Prohens et al., 2007). According to a recent study on 12 indigenous commonly consumed vegetables of Bangladesh reported that TPC of S. melongena was $271 \mathrm{mg} \mathrm{GAE} / 100 \mathrm{~g}$ of fresh sample in green variety and $394 \mathrm{mg}$ GAE/100 g in violet one (Sharmin et al., 2011).

\section{DPPH and ABTS radical scavenging activities}

The DPPH and ABTS radical scavenging assays measure the relative antioxidant efficacy of natural extracts in scavenging free radicals ( $\mathrm{DPPH}$ and $\mathrm{ABTS}^{+}$, respectively) generated in the assay medium (Apak et al., 2007). The degree of discolouration is an indication of the scavenging capacity of the extracts. The extracts were able to reduce the stable violet DPPH radical to yellow DPPH-H over a range of concentrations $(0.94-5.63 \mathrm{mg} / \mathrm{ml})$. An increase in sample concentration significantly increased the DPPH radical scavenging activity of samples in a dose dependent manner as shown in Figure 2.

The $\mathrm{IC}_{50}$ value represents the amount of antioxidative constituents required to scavenge $50 \%$ of free radical in the assay system. The lower the $\mathrm{IC}_{50}$ value, the greater is the antioxidant activity. The results showed that there was a significant difference $(\mathrm{P}<0.0001)$ between the samples and DPPH radical scavenging activity. The $\mathrm{IC}_{50}$ values of the extracts ranged from $3.51 \pm 0.62$ to $4.87 \pm 1.47 \mathrm{mg} / \mathrm{ml}$ (Table 1). The highest antioxidant activity was recorded in $\mathrm{S} 1$ followed by S3 and S5. The least antioxidant activity was recorded in S2 and S4. The $\mathrm{IC}_{50}$ values for S2 and $\mathrm{S} 4$ were $4.78 \pm 0.65$ and $4.87 \pm 1.47 \mathrm{mg} / \mathrm{ml}$ respectively and were not significantly different. The $\mathrm{IC}_{50}$ value of ascorbic acid was observed to be very low (1.86 $\mu \mathrm{g} / \mathrm{ml}$ ) indicating significantly higher antioxidant activity compared to different brinjal varieties used in the study. Difference in scavenging activities might be due to the presence of different phenolic compounds and the difference in the total phenolic.

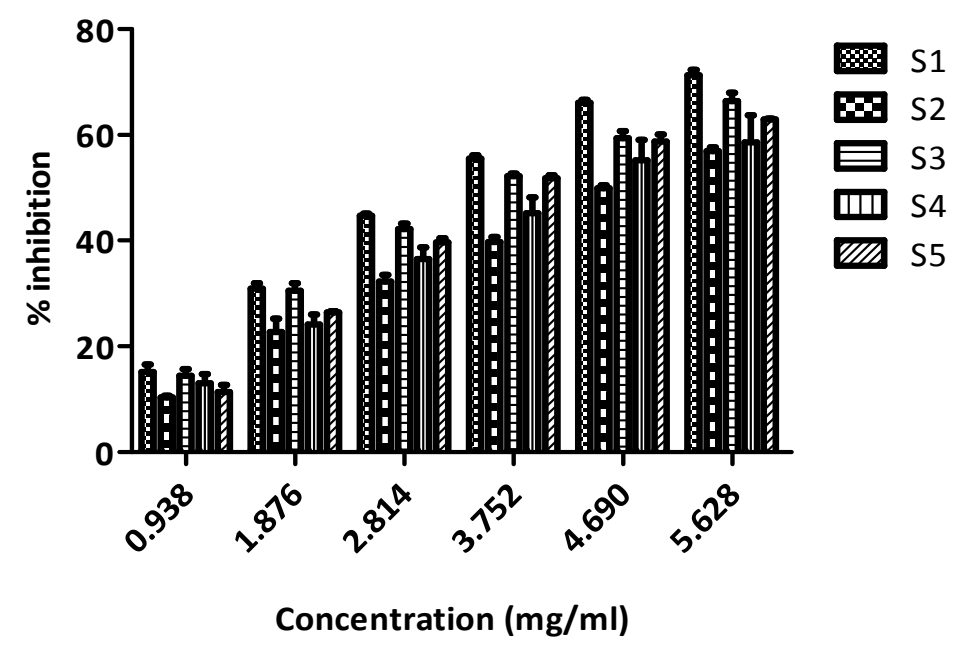

Fig. 2. DPPH radical scavenging activity of brinjal extracts at various concentrations. Each bar represents mean + SD $(n=4)$. 
Generation of $\mathrm{ABTS}^{\cdot+}$ involves direct production of the blue/green $\mathrm{ABTS}^{\cdot+}$ chromophore through the reaction between ABTS and potassium persulfate/AAPH. Addition of antioxidants to the pre-formed radical cation reduces it to ABTS, based on the concentration of the antioxidant and the duration of the reaction. Thus, an increase in time and concentration significantly increases the radical scavenging activity. The brinjal extracts showed potent antioxidant activity in scavenging the ABTS radicals over 6 minutes. The S3 extract displayed the highest total antioxidant activity of $40.45 \% \pm 1.17$ at a concentration of $25 \mathrm{mg} / \mathrm{ml}$ which was significantly higher than all other tested extracts. Total antioxidant capacity of S2 was significantly lower than all other extracts while, the activity of S1, S4 and S5 was not significantly different $(\mathrm{p}>0.0001)$ (Table 1). Ascorbic acid showed the highest total antioxidant capacity of $85.79 \% \pm 1.91$ at a concentration of $0.01 \mathrm{mg} / \mathrm{ml}$.

\section{FRAP assay}

The FRAP assay measures the reducing potential of an antioxidant reacting with ferric tripyridyltriazine $\left(\mathrm{Fe}^{3+}-\mathrm{TPTZ}\right)$ complex and producing a coloured ferrous tripyridyltriazine (Fe ${ }^{2+}$-TPTZ) (Kriengsak et al., 2006). The FRAP assay showed a positive correlation between reducing power and phenolic content in brinjal extracts. The ferric reducing antioxidant power activity of $S$. melongena is presented in Table 1 . The S3 extract showed the highest FRAP value of $7.46 \pm 0.26 \mathrm{mmol}$ of $\mathrm{Fe}^{2+} / \mathrm{g}$ fresh sample. The antioxidant potential of brinjal extracts as measured by FRAP followed the order of $\mathrm{S} 3>\mathrm{S} 1>\mathrm{S} 5=\mathrm{S} 4>\mathrm{S} 2$. On the contrary, the FRAP value for ascorbic acid $\left(1.43 \pm 0.04 \mathrm{mmol}\right.$ of $\left.\mathrm{Fe}^{2+} / \mathrm{g}\right)$ was significantly lower than that of brinjal extracts. It is clear from the results that the FRAP activity of S3 and S1 was the highest among all the brinjal extracts studied.

\section{Ferric Thiocyanate (FTC) test}

The antioxidant potential of brinjal extracts was evaluated by measuring inhibition of lipid peroxidation in linoleic acid system. The percent inhibition of linoleic acid peroxidation of water extracts of brinjal is illustrated in Figure 3. From the analysis, it is evident that all samples had been oxidized when stored over seven days at $40-45^{\circ} \mathrm{C}$. Absorbance of each sample increased progressively with the time of incubation. Lower absorbance values indicate higher antioxidant activities.

The results showed that there was a significant difference $(\mathrm{p}<0.0001)$ between skin colour and antioxidant activity as measured by FTC assay. The percent inhibition increased from day 1 to day 3 and the subsequent measurements were not coherent. The highest antioxidant activity was observed on day 3 for all extracts, except for $\mathrm{S} 1$, where the highest activity was observed on day $4(30.28 \% \pm 0.85)$. Of the five extracts tested, the highest antioxidant activity was observed in S1 which exhibited $26.74 \% \pm 2.85$ inhibition on day 3 and the lowest value was recorded in S2 $(15.11 \% \pm 1.31)$ at a concentration of $25 \mathrm{mg} / \mathrm{ml}$. The antioxidant activity of $25.36 \% \pm 1.01$ was shown by S3 which was not significantly different $(\mathrm{p}>0.0001)$ from those of S1 and S4. The higher inhibition potential of S1 and S3 against linoleic acid peroxidation can be attributed to the presence of higher amounts of phenolic bioactives (Zainol et al., 2003). 


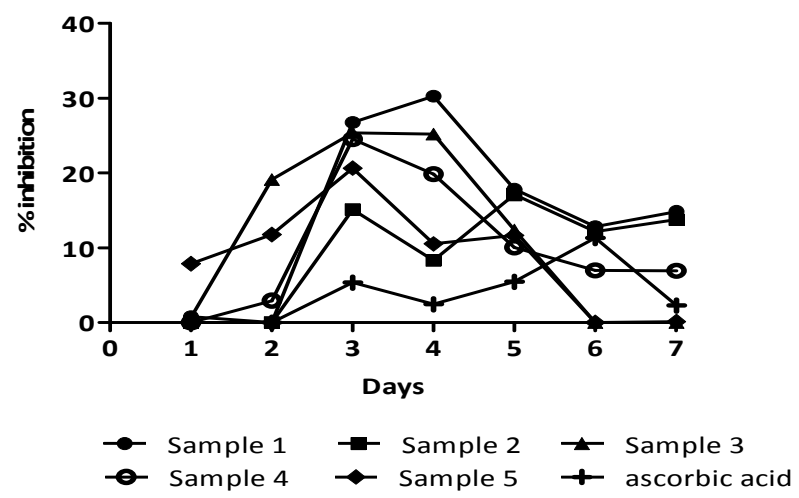

Fig 3. Antioxidant activity of brinjal extracts and ascorbic acid determined by the FTC method.

The inhibition of lipid oxidation by the reference ascorbic acid was $5.37 \% \pm 1.08$ at a concentration of $0.01 \mathrm{mg} / \mathrm{ml}$. This was significantly $(\mathrm{p}<0.0001)$ lower than all brinjal extracts. Until day 3, ascorbic acid did not show any inhibition potential. The absorbance values were higher than control, indicating pro-oxidant activity.

The brinjal extracts, S1, S3 and S5 started to show inhibition of lipid peroxidation from the first day while the other samples started to inhibit oxidation from day 2. This observation is in line with the study carried out by Huda-Faujan et al. (2009), where the absorbance of control was lower than the samples till day 4. After day 5, S3 and S5 did not show any inhibition while the activity of the other extracts also declined. The effectiveness of the reference antioxidant was generally lower than that of the extracts. Formation of peroxides ceased during the incubation period due to non-availability of linoleic acid. Also, the intermediate products might have been converted to stable end-products. The nonavailability of hydroperoxides resulted in the stoppage of oxidation of ferrous sulphate. Hence, the optical density declined.

\section{Relationship between phyto-chemical content and antioxidant activities}

Previous studies have demonstrated the strong relationship between total phenolic content and antioxidant activities found in different crops (Yang et al., 2004; Kriengsak et al., 2006). In the present study, a significant correlation was observed between total phenolic content found in S1-S5 and the DPPH, ABTS, FRAP and FTC assays (Figure 4). These results indicated that total phenolic content may be in part responsible for the antioxidant activities of brinjal tested. 


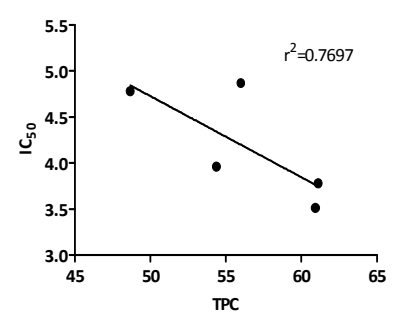

(a)

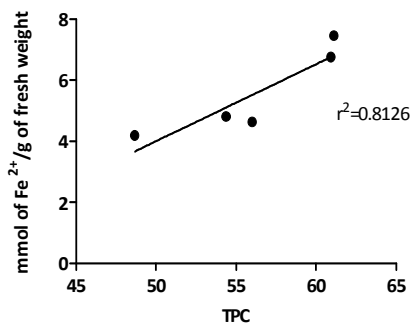

(c)

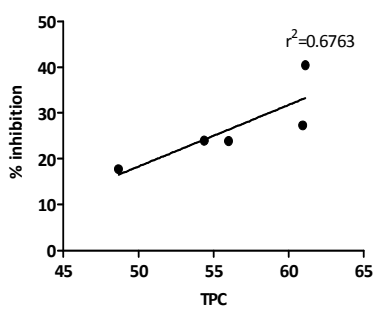

(b)

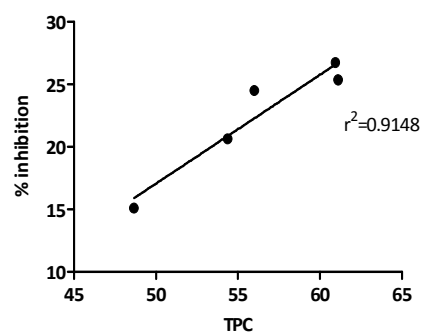

(d)

Fig. 4. Correlation between TPC and (a) DPPH radical scavenging activity (b) ABTS radical scavenging activity (c) FRAP assay and (d) FTC of five brinjal types

Anthocyanins are the main phenolic compounds in eggplant peel (Jung et al., 2011). The total anthocyanin content in purple colour brinjal variety was found to be markedly higher than the green variety (Nisha et al., 2009). Whitaker and Stommel (2003) examined the phenolic acid content of the fruit flesh of seven commercial brinjal cultivars and found significant differences in the phenolic content and composition among cultivars and in tissue from stem, middle, and blossom end segments. Therefore, the high diversity in the variety of phenolic compounds as well as the proportions of phenolic compounds contained in individual brinjal varieties probably explains the differences in the antioxidant activities of S1-S5 observed in the present study.

\section{CONCLUSION}

The present study demonstrated that all aqueous extracts of brinjal exhibit potent antioxidant activity and apparently, the antioxidant properties of all five types of brinjal positively correlate with their polyphenolic content. From all these observations it appears that S1 and S3, intensely coloured skins, shows greater antioxidant activity than lighter ones. 


\section{REFERENCES}

Apak, R., Guclu, K., Demirata, B., Ozyurek, M., Celik, S., Bektaflo lu, B., Berker, K. and Ozyurt, D. (2007). Comparative evaluation of various total antioxidant capacity assays applied to phenolic compounds with the CUPRAC assay. Molecules, 12, $1496-1547$.

Brand-Williams, W., Cuvelier, M.E. and Berset, C. (1995). Use of free radical method to evaluate antioxidant activity. Lebensm.-Wiss. Technol. 28, 25 - 30.

Brown, C.R. (2005). Antioxidants in potato. Amer. J. Pot. Res. 82(2), 105 - 177.

Cao, G., Sofic, E. and Prior, R. (1996). Antioxidant capacity of tea and common vegetables.J. Agric. Food Chem. 44(11), 3426 - 3431.

Huda-Faujan, N., Noriham, A., Norrakiah, A. S. and Babji, A. S. (2007). Antioxidative activities of water extracts of some Malaysian herbs. ASEAN Food J. 14(1), 61 - 68.

Huda-Faujan, N., Noriham, A., Norrakiah, A.S. and Babji, A.S. (2009). Antioxidant activity of plants methanolic extracts containing phenolic compounds. Afr. J. Biotechnol. 8(3), 484 489.

Jang, I.C., Jo, E.K., Bae, M.S., Lee, H.J., Jeon, G.I., Park, E., Yuk, H.G., Ahn, G.H. and Lee, S.C. (2010). Antioxidant and antigenotoxic activities of different parts of persimmon (Diospyros kaki cv. Fuyu) fruit. J. Med. Plant Res. 4, 155 - 160.

Jung, E.J., Bae, M.S., Jo, E.K., Jo, Y.H. and Lee, S.C. (2011). Antioxidant activity of different parts of eggplant. J. Med. Plant Res. 5(18), 4610 - 4615.

Kaneyuki, T., Noda, Y., Traber, M.G., Mori, A. and Packer, L. (1999). Superoxide anion and hydroxyl radical scavenging activities of vegetable extracts measured using electron spin resonance. Biochem. Mol. Biol. Int. 47, 979 - 989.

Keli, S.O., Hertog, M.G.L., Feskens, E.J.M. and Kromhout, D. (1996). Dietary flavonoids, antioxidant vitamins and incidence of stroke: the Zutphen study. Arch. Int. Med. 156, 637642.

Knekt, P., Jarvinen, R., Reunanen, A. and Maatela, J. (1996). Flavonoid intake and coronary mortality in Finland: a cohort study. Br. Med. J. 312, 478 - 481.

Knekt, P., Jarvinen, R., Seppanen, R., Heliovaara, M., Teppo, L., Pukkala, E. and Aromaa, A. (1997). Dietary flavonoids and the risk of lung cancer and other malignant neoplasms. Am. J. Epidemiol. 146, 223 - 230.

Kriengsak, T., Unaroj, B., Kevin, C., Luis, C. and David, H.B. (2006). Comparison of ABTS, DPPH, FRAP, and ORAC assays for estimating antioxidant activity from guava fruit extracts. J. Food Comp. Anal. 19, 669 - 675.

Matsubara, K., Kaneyuki, T., Miyake, T. and Mori, M. (2005). Antiangiogenic activity of nasunin, an antioxidant anthocyanin in eggplant peels. J. Agric. Food Chem. 53, 6272 - 6275. 
Nisha, P., Abdul Nazar, P. and Jayamurthy, P. (2009). A comparative study on antioxidant activities of different varieties of Solanum melongena. Food Chem. Toxicol. 47, 2640 - 2644.

Noda, Y., Kaneyuki, T., Igarashi, K., Mori, A. and Packer, L. (2000). Antioxidant activity of nasunin, an anthocyanin in eggplant peels. Toxicol. 148, 119 - 123.

Prohens, J., Rodriguez-Burruezo, A., Raigon, MD. and Nuez, F. (2007). Total Phenolic Concentration and Browning Susceptibility in a Collection of Different Varietal Types and Hybrids of Eggplant: Implications for Breeding for Higher Nutritional Quality and Reduced Browning. J. Amer. Soc. Hort. Sci. 132(5), 638 - 646.

Robereta, R., Nicoletta, P., Anna, P., Ananth, P., Min, Y. and Catherine, R. (1999). Antioxidant activity applying an improved ABTS radical cation decolouration assay. J. Free Radic. Biol. Med. 26(9/10), 1231 - 1237.

Sawa, T., Nakao, M., Akaike, T., Ono, K. and Maeda, H. (1998). Alkylperoxyl radicalscavenging activity of various flavonoids and other phenolic compounds: Implications for the anti-tumor-promoter effect of vegetables. J. Agric. Food Chem. 47, 397 - 402.

Sharmin, H., Nazma, S., Mohiduzzaman, M. and Banu, C.P. (2011). Antioxidant capacity and total phenol content of commonly consumed selected vegetables of Bangladesh. Mal. J. Nutr. 17(3), 377 - 388.

Singh, A.P., Luthria, D., Wilson, T., Vorsa, N., Singh, V., Banuelos, G.S. and Pasakdee, S. (2009). Polyphenols content and antioxidant capacity of eggplant pulp. Food Chem. 114, 955 $-961$.

Tomás-Barberán, F.A., Gil, M.I., Cremin, P., Waterhouse, A.L., Hess-Pierce, B. and Kader, A.A. (2001). HPLC-DAD-ESIMS Analysis of phenolic compounds in nectarines, peaches, and plums. J. Agric. Food Chem. 49, 4748 - 4760.

Triantis, T., Stelakis, A., Dimotikali, D. and Papadopoulos, K. (2005). Investigations on the antioxidant activity of fruit and vegetable aqueous extracts on superoxide radical anion using chemiluminiscence techniques. Anal. Chim. Acta. 536, $101-105$.

Vinson, J.A., Hao, Y., Su, X. and Zubik, L. (1998). Phenol antioxidant quantity and quality in foods: vegetables. J. Agric. Food Chem. 46, 3630 - 3634.

Whitaker, B.D., and Stommel, J.R. (2003). Phenolic acid content and composition of eggplant fruit in a germplasm core subset. J. Am. Soc. Hortic. Sci. 128, 704 - 710.

Yang, J., Meyers, K.J., van der Heide, J. and Liu, R.H. (2004). Varietal differences in phenolic content and antioxidant and antiproliferative activities of onions. J. Agric. Food Chem. 52, 6787 - 6793.

Zainol, M.K., Abd-Hamid, A., Yusof, S. and Muse, R. (2003). Antioxidative activity and total phenolic compounds of leaf, root and petiole of four accessions of Centella asiatica L. Urban. Food Chem. 81, 575 - 581. 